\title{
DOCUMENTATION PROTOCOLS TO GENERATE RISK INDICATORS REGARDING DEGRADATION PROCESSES FOR CULTURAL HERITAGE RISK EVALUATION
}

\author{
A. Kioussi ${ }^{\text {a, } *, \text { M. Karoglou }}{ }^{\text {a }}$, A. Bakolas ${ }^{\text {a }}$, K. Labropoulos, A. Moropoulou ${ }^{\text {a }}$
}

\author{
${ }^{\text {a }}$ NTUA- National Technical University of Athens, School of Chemical Engineering, Iroon Polytechniou Str. 9, \\ 15780 Athens, Greece - (nasiak@central.ntua.gr, margo@central.ntua.gr, abakolas@central.ntua.gr, klabrop@central.ntua.gr, \\ amoropul@central.ntua.gr)
}

KEY WORDS: Cultural Heritage, Documentation, Risks, Vulnerability, Degradation Processes, Risk Indicators

\begin{abstract}
:
Sustainable maintenance and preservation of cultural heritage assets depends highly on its resilience to external or internal alterations and to various hazards. Risk assessment of a heritage asset's can be defined as the identification of all potential hazards affecting it and the evaluation of the asset's vulnerability (building materials and building structure conservation state).Potential hazards for cultural heritage are complex and varying. The risk of decay and damage associated with monuments is not limited to certain long term natural processes, sudden events and human impact (macroscale of the heritage asset) but is also a function of the degradation processes within materials and structural elements due to physical and chemical procedures. Obviously, these factors cover different scales of the problem. The deteriorating processes in materials may be triggered by external influences or caused because of internal chemical and/or physical variations of materials properties and characteristics. Therefore risk evaluation should be dealt in the direction of revealing the specific active decay and damage mechanism both in mesoscale [type of decay and damage] and microscale [decay phenomenon mechanism] level. A prerequisite for risk indicators identification and development is the existence of an organised source of comparable and interoperable data about heritage assets under observation. This unified source of information offers a knowledge based background of the asset's vulnerability through the diagnosis of building materials' and building structure's conservation state, through the identification of all potential hazards affecting these and through mapping of its possible alterations during its entire life-time. In this framework the identification and analysis of risks regarding degradation processes for the development of qualitative and quantitative indicators can be supported by documentation protocols. The data investigated by such protocols help identify the parameters needed for the assessment of the preservation state of a monument and its monitoring through its entire lifetime. The main tool for detecting these indicators is a diagnostic methodology based on appropriate standards that reveals the actual degradation processes responsible of the asset's vulnerability. It is very important that the integration between the material's diagnosis and the overall documentation is taken into consideration in order to identify the required levels of protection and preventive conservation for heritage assets depending on the most frequent local risks. The ranging of risks is therefore necessary according to their importance in each area. Documentation protocols provide with a specific diagnostic tool for materials characterization, decay diagnosis, evaluation process of former conservation materials and interventions, standard procedures for monitoring and control as well as data documentation based on specific guidelines and standards. Implementation and analysis of a "standardised" diagnostic study will reveal the main risks due to degradation processes affecting the heritage asset to be subsequently recorded in order to result into risk indicators. The development of risk indicators regarding degradation processes is the basic step towards uptaking efficient management, preventive conservation and strategic planning for heritage assets against various threats. These risk indicators could be further elaborated according to the activities of inspection, diagnosis and intervention works, offering scientific support to the decision making process for cultural heritage preventive conservation and overall protection.
\end{abstract}

\section{INTRODUCTION}

\subsection{Motivation}

Cultural Heritage management regarding an asset's preventive conservation and overall protection requires the employment of risk evaluation in order to result in the most appropriate critical decisions. The approach of risk evaluation could be defined as the correlation and function of the identified hazards, according to the geographic and environmental specificities of heritage assets, and the detailed analysis of their vulnerability (building materials and building structure conservation state). (Stovel, $\mathrm{H}$. 1998), (Accardo, G. et al., 2003), (Mazzolani, F., 2010).

\subsection{Aim of this work}

The development of a standard approach regarding risk assessment regarding degradation processes is the basic step towards developing efficient protection and management strategies for heritage assets, through the uptake of appropriate measures that are able to upgrade the heritage asset's resilience against various threats. The aim is to contribute to the identification of risks and methods for assessment of vulnerability of heritage assets exposed to danger. The main hazards for cultural heritage assets as well as the attributes of its vulnerability are being analysed in order to deliver the criteria that help prioritize all risk factors affecting the state of conservation of cultural heritage and to elaborate them into

\footnotetext{
* Corresponding author. This is useful to know for communication with the appropriate person in cases with more than one author.
} 
becoming risk indicators able to warn and advise about an asset's susceptibility to degradation processes and therefore its reduced strength.

\subsection{Overview}

In order to explore the current directives and methodologies employed and applied in the field of risk assessment through hazard identification and evaluation of a building's conservation state, an extended research was conducted, on existing directives for risk assessment related to monument conservation. The main objective was to become aware of the identified hazards for monuments, the main vulnerability attributes as well as the currently applicable risk assessment methodologies. The outcome revealed that the risk of decay and damage associated with monuments can not limited to certain environmental dangers, static/structural, human impact and natural hazards, but is also a function of various other factors such as the conservation state of the materials (i.e. not only the static/structural aspects of the building), the importance and distribution of cultural heritage, the impact factor of the hazards present, various socioeconomic parameters etc. Obviously, these factors cover different scales of the problem. In particular, there is a correlation between decay and damage of materials that often leads to the monuments pathology. The deteriorating processes in materials and structures may be triggered by external influences or caused because of internal chemical and/or physical time-depending variations of characteristics of material. Therefore risk assessment should be dealt in the direction of revealing the specific active decay mechanism with an integrated decay study both in mesoscale [type of decay and damage] and microscale [decay phenomenon mechanisms (kinetics, thermodynamics, structural etc) (Moropoulou, et al 2012), (Kioussi et al., 2011).

\section{METHODOLOGICAL APPROACH}

A prerequisite for risk identification is the existence of an organised source of reliable, comparable and interoperable data about heritage assets under observation. In this framework the identification and analysis of risks regarding degradation processes for the development of qualitative and quantitative indicators can be supported by integrated documentation. Integrated documentation protocols assist proper data collection, classification and presentation, enable understanding and knowledge on the heritage asset (including its history, value assessment, state of conservation, structural condition as well as all previous restoration works, risks identification and assessment of its vulnerability by environmental and human causes) as well as monitoring and systematic reporting on alterations taking place during its entire lifetime (Figure 1) [Kioussi, et al 2013a].

More specifically, the protocols of advanced diagnostics, part of the integrated documentation protocols, provide with the guidelines for revealing the actual degradation processes responsible for the asset's vulnerability, based on the requirements of a typical diagnostic study and structural analysis methodology, generated by a necessity for quality control application in building and/or conservation materials and structures and having been harmonized with appropriate standards, in order to minimize structural faults, and enhance effectiveness of conservation and protection interventions (Figure 2) (Binda, et al, 2000), (Moropoulou, et al 2003), (Kioussi, et al 2013b).

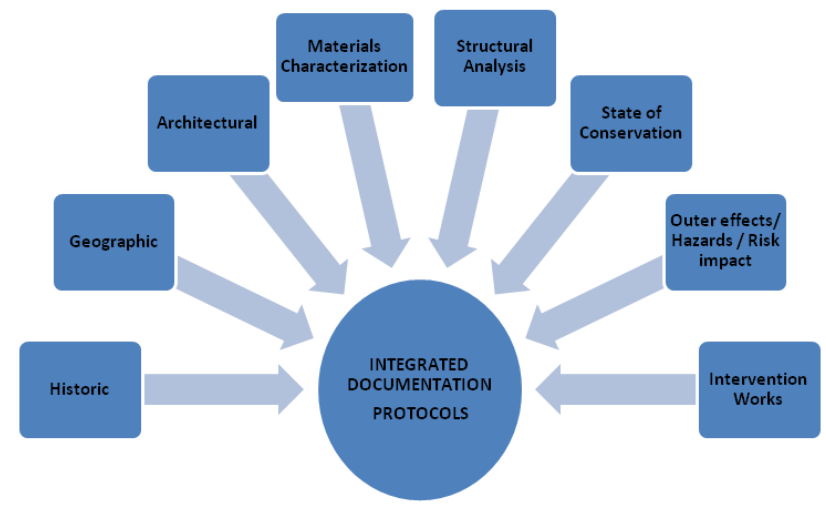

Figure 1. Integrated Documentation protocols data categories

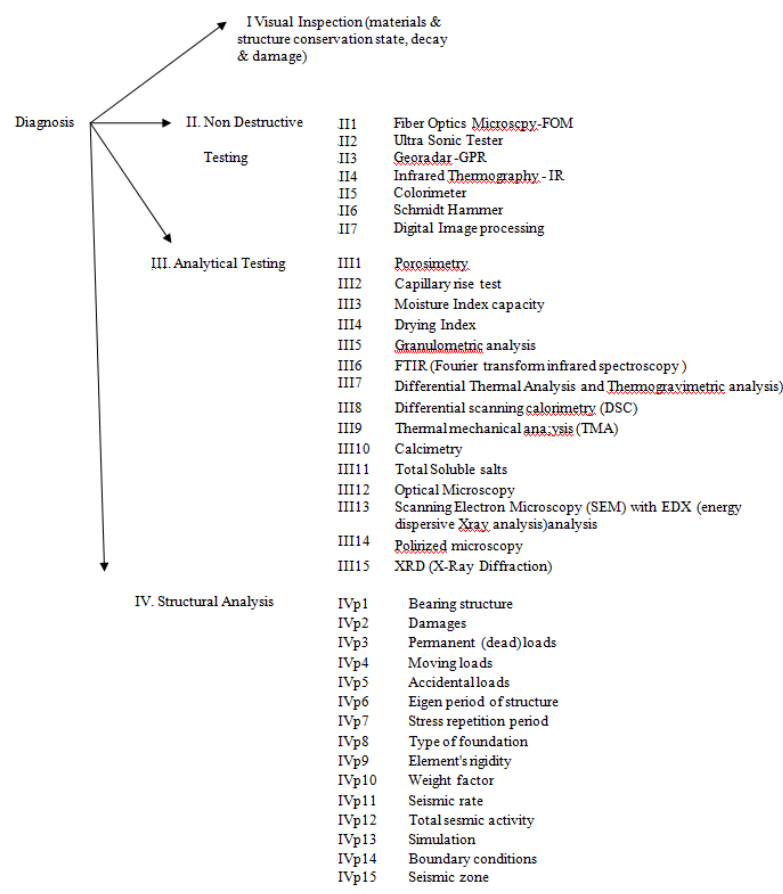

Figure 2. Integrated Protocols of Advanced Diagnostics data categories and parameters

It is very important that the integration between the material's diagnosis and the overall documentation is taken into consideration in order to identify the required levels of preventive conservation and protection for heritage assets depending on the most frequent local risks.

\section{DEGRADATION PROCESSES}

The detection of wear and degradation of building materials includes the determination of decay products and damages. The decay of building materials can be defined as the degradation over time of the materials' properties (physical, chemical, mechanical, etc.) and characteristics (mineralogical, texture, etc.), leading to their failure as building components. Decay phenomena develop at the interface of materials with the environment or at the interface of materials with other materials and are a function of intrinsic and extrinsic factors. The analysis of these factors is essential to the study of the decay pathology of the monument and for the detection of the actual risks affecting it (Moropoulou A., Labropoulos K., 2010) 
Intrinsic factors include the type of building materials, their properties, their mass distribution, their origin and the processing technology, their "history" (prior conservation interventions) and their compatibility with other materials. Extrinsic factors include the climate characteristics (distribution, orientation, and amplitude of environmental factors), the prevailing microclimate, the type of the atmosphere (urban, marine, etc.), the action of water (aerosol, rain, rising damp, condensation, and salt crystallization) and the monument's static and dynamic loading patterns. The analysis of the state of conservation relates to all data regarding the diagnosis of the monuments decay using visual observations, non-destructive techniques, a large array of analytical techniques, GIS decay mapping, etc., both on structural and non structural elements of the monument. Information on the decay forms and mechanisms as well as on the vulnerability diagnosis [e.g static analysis, etc.] are also collected and stored to complete assessment of the an overall state of conservation.
Implementation and analysis of a typical diagnostic study and a structural analysis will reveal the main risks affecting the heritage asset to be subsequently processed in order to result into risk indicators (Moropoulou, et al 2013).

The table below (Table 1) presents the group of factors that participate in the degradation process and can be evaluated as major or minor risks for the building materials and structures, further subdivided and analysed to individual, more specific, parameters. In this way a documentation protocol of materials and structure decay is formulated, comprising the visual documentation of decay, the main decay forms / types, the decay mechanisms as well as the intrinsic and extrinsic factors of degradation (ICOMOS, 2008).

\begin{tabular}{|c|c|c|}
\hline \multirow{28}{*}{$\begin{array}{l}\text { PROTOCOL OF } \\
\text { DECAY } \\
\text { INVESTIGATION }\end{array}$} & \multirow{3}{*}{$\begin{array}{l}\text { VISUAL OBSERVATIONS OF } \\
\text { BUILDING MATERIALS } \\
\text { STATE CONSERVATION }\end{array}$} & Visual inspection general data \\
\hline & & Building material general data \\
\hline & & Decay general data \\
\hline & \multirow{4}{*}{$\begin{array}{l}\text { TYPOLOGY OF } \\
\text { DETERIORATION } \\
\text { PHENOMENA }\end{array}$} & Various Crusts \\
\hline & & Cracks and \\
\hline & & Loss of material \\
\hline & & Biological deterioration \\
\hline & \multirow{3}{*}{ DECAY MECHANISMS } & Physical / Mechanical Processes \\
\hline & & Physicochemical Processes \\
\hline & & Chemical and Biochemical Processes \\
\hline & \multirow{8}{*}{$\begin{array}{l}\text { DECAY INTRINSIC } \\
\text { FACTORS }\end{array}$} & Building materials general data \\
\hline & & Building materials type \\
\hline & & Natural building materials \\
\hline & & Artificial building materials \\
\hline & & $\begin{array}{l}\text { Building materials Mineralogical - } \\
\text { Petrographic Characterization }\end{array}$ \\
\hline & & Building materials Physical Characterization \\
\hline & & Building materials Life Cycle \\
\hline & & Building materials Techno economic data \\
\hline & \multirow{10}{*}{$\begin{array}{l}\text { DECAY EXTRINSIC } \\
\text { FACTORS }\end{array}$} & Structure general data \\
\hline & & Climate data \\
\hline & & Atmospheric conditions \\
\hline & & Indoor Environment \\
\hline & & Biological Factors \\
\hline & & Accidental actions \\
\hline & & Human Impact \\
\hline & & Condition of usage \\
\hline & & Socioeconomic Parameters \\
\hline & & Geotechnical frame of foundation \\
\hline
\end{tabular}

Table 1. Protocol of Decay Investigation

\section{RISKS IDENTIFICATION - RISK INDICATORS DEVELOMENT}

Risk indicators development focused on degradation processes, require a series of steps in order to result in a set of specifically described, measurable and clearly interpreted indicators.

- The first step comprises the identification of a risk that affect the heritage asset
- Next comes the detailed analysis of the risk, including its characteristics, particularities as well as the mechanism of affecting the heritage asset

- Then follows the evaluation of the identified risk in order to be classified within the final ranking of risks

- The subsequent step is the assignment of a quantitative or qualitative designation to the risk

- The final step includes the management of risk, proposals for efficient response to it as well as preventive 
conservation regarding vulnerability, or further development into risk indicator

In this work a set of criteria, concerning both intrinsic and extrinsic risk factors and deriving from the protocol of advanced diagnostics, is selected and assigned with qualitative and quantitative designation to the risk. Within this process the simple criteria of risk analysis are further elaborated into transforming to risk indicators able to inform about an asset's resilience to various impacts and loads.

The selection of certain parameters against other was mainly based on the fact that while some of them refer to the tendency of the materials to degradation and not necessarily to the actual state of preservation, others reflect the alteration of characteristics of weathered compared with healthy / quarry materials and therefore are more indicative of the degree of wear which have undergone and hold a greater weighing factor of the overall degradation process. It is therefore necessary to establish critical limits and the adoption of appropriate scale for each characteristic parameter to distinguish the range of values of each parameter in risk levels (level of risk) as to the state of the material (Chela, G., 2006).

The selected parameters are: Microstructure characteristics alteration, Total soluble salts, Anions type and concentration, Visual observations - surface deterioration, Visual observations - qualitative, Ultrasonic velocity propagation, Environmental characterization, Architectural surface.

The following step in the process of developing specific Risk Indicators (hereinafter denoted as RI) from these risk parameters requests the establishment of critical limits which determine whether deterioration level is accepted or not (Tables 2-12). The scale applied is $1-5,1$ being the lowest limit and 5 the highest limit.

$>\quad$ Microstructure parameters variation (\%) RI.1: concerns the parameters variation of decayed materials microstructure, like the total cumulative volume, bulk density, total open porosity and the average pore radius as well as specific surface area of the tested materials, in respect to healthy material.

\begin{tabular}{|c|c|c|c|c|c|}
\hline RI.1 & 1 & 2 & 3 & 4 & 5 \\
\hline Total & $\Delta \mathrm{V}$ & $5<\Delta$ & $8<\Delta$ & $12<\Delta \mathrm{V} \% \leq 20$ & $20<\Delta \mathrm{V}$ \\
Cumula & $\% \leq$ & $\mathrm{V} \%$ & $\mathrm{~V} \%$ & & $\%$ \\
ted & 5 & $\leq 8$ & $\leq 12$ & & \\
Volume & & & & & \\
(V\%) & & & & & \\
\hline Bulk & $\Delta \mathrm{d}$ & $2<\Delta$ & $3<\Delta$ & $5<\Delta \mathrm{d} \% \leq 10$ & $10<\Delta \mathrm{d}$ \\
Density & $\% \leq$ & $\mathrm{d} \%$ & $\mathrm{~d} \%$ & & $\%$ \\
(d\%) & 2 & $\leq 3$ & $\leq 5$ & & \\
\hline Total & $\Delta \mathrm{P}$ & $5<\Delta$ & $8<\Delta$ & $12<\Delta \mathrm{P} \% \leq 20$ & $20<\Delta \mathrm{P}$ \\
Open & $\% \leq$ & $\mathrm{P} \%$ & $\mathrm{P} \%$ & & $\%$ \\
Porosit & 5 & $\leq 8$ & $\leq 12$ & & \\
$\mathrm{y}$ & & & & & \\
(P\%) & & & & & \\
\hline Averag & $\Delta \mathrm{r} \%$ & $1<\Delta$ & $2<\Delta$ & $3<\Delta \mathrm{r} \% \leq 5$ & $5<\Delta \mathrm{r} \%$ \\
e Pore & $\leq 1$ & $\mathrm{r} \% \leq$ & $\mathrm{r} \% \leq$ & & \\
Radius & & 2 & 3 & & \\
(r\%) & & & & & \\
\hline Specific & $\Delta \mathrm{SS}$ & $2<\Delta$ & $3<\Delta$ & $4<\Delta \mathrm{SSA} \% \leq 7$ & $7<\Delta \mathrm{SS}$ \\
Surface & & & & & \\
\hline
\end{tabular}

\begin{tabular}{|c|c|c|c|l|c|}
\hline Area & A\% & SS & SS & & A\% \\
$($ SSA $\%)$ & $\leq 2$ & A\% & A\% & & \\
& & $\leq 3$ & $\leq 4$ & & \\
\hline
\end{tabular}

Table 2. Microstructure parameters variation

$>\quad$ Total soluble salts TSS\% RI.2: concerns the concentration of total soluble salts, as an important decay risk indicator. The content is determined in respect to the material's dry mass.

\begin{tabular}{|c|c|c|c|c|c|}
\hline RI.2 & 1 & 2 & 3 & 4 & 5 \\
\hline TSS\% & $\leq 3$ & $3<\mathrm{T}$ & $4<$ & $6<\mathrm{TSS} \% \leq 8$ & TSS\%>8 \\
& & $\begin{array}{c}\text { SS } \% \\
\leq 4\end{array}$ & $\begin{array}{c}\text { TSS } \\
\% \leq 6\end{array}$ & & \\
& & & \\
\hline
\end{tabular}

Table 3. Total soluble salts content TSS\%

$>\quad$ Anions type and concentration $\mathrm{Cl}, \mathrm{SO}_{4}, \mathrm{NO}_{3}, \underline{\text { RI.3: }}$ concerns the concentration of the main anions such as chlorides, sulphates and nitrates. The content is determined in respect to the material's dry mass.

\begin{tabular}{|c|c|c|c|c|c|}
\hline RI.3a & 1 & 2 & 3 & 4 & 5 \\
\hline $\begin{array}{l}{[\mathrm{Cl}]} \\
(\%)\end{array}$ & $\leq 0,3$ & $\begin{array}{l}0,3< \\
\mathrm{Cl}<0 \\
, 4 \\
\end{array}$ & $\begin{array}{l}0,4 \leq \mathrm{Cl} \\
<0,6\end{array}$ & $0,6 \leq \mathrm{Cl}<0,8$ & $\begin{array}{l}0,8 \leq \\
\mathrm{Cl}\end{array}$ \\
\hline $\begin{array}{l}{[\mathrm{SO} 4]} \\
(\%)\end{array}$ & $\leq 0,8$ & $\begin{array}{l}0,8< \\
\mathrm{SO} 4 \\
<1 \\
\end{array}$ & $\begin{array}{l}1 \leq \mathrm{SO} 4 \\
<1.3\end{array}$ & $1,3 \leq \mathrm{SO} 4<1.6$ & $\begin{array}{l}1,6 \leq \mathrm{S} \\
\mathrm{O} 4\end{array}$ \\
\hline $\begin{array}{l}\text { [NO3] } \\
(\%)\end{array}$ & $\begin{array}{l}\leq 0,1 \\
2\end{array}$ & $\begin{array}{l}0,12 \\
<\mathrm{NO} \\
3<0, \\
20\end{array}$ & $\begin{array}{l}, 20 \leq \mathrm{N} \\
\mathrm{O} 3<0,3 \\
5\end{array}$ & $\begin{array}{l}0,35 \leq \mathrm{NO} 3<0, \\
50\end{array}$ & $\begin{array}{l}0,5 \leq \\
\text { NO3 }\end{array}$ \\
\hline
\end{tabular}

Table 4. Quantitative determination of the anions 'soluble fraction

\begin{tabular}{|l|c|c|c|c|c|}
\hline \multicolumn{1}{|c|}{$\mathbf{R I . 3 b}$} & 1 & 2 & 3 & 4 & 5 \\
\hline$[\mathrm{Cl}]$ & + & ++ & +++ & ++++ & +++++ \\
\hline$[\mathrm{SO} 4]$ & + & ++ & +++ & ++++ & +++++ \\
\hline$[\mathrm{NO} 3]$ & + & ++ & +++ & ++++ & +++++ \\
\hline
\end{tabular}

Table 5. Semi quantitative determination of the anions 'soluble fraction

D Decay patterns mapping RI.4: concerns the surface decay mapping using various mapping techniques such as photography, photogrammetry etc., resulting to the in the quantification of micro cracks, crusts, exfoliations, detachments, alveolar decay, etc. This is achieved by estimating the percentage of the surface area occupied by each of the above decay types in relation to the appropriate weighting factor.

\begin{tabular}{|l|l|l|l|l|l|}
\hline RI.4 & 1 & 2 & 3 & 4 & 5 \\
\hline $\begin{array}{l}\text { Decayed } \\
\text { surface area } \\
\text { (Atot\%) }\end{array}$ & $\leq 5$ & $\begin{array}{l}5<\mathrm{At} \\
\text { ot } \% \leq \\
15\end{array}$ & $\begin{array}{l}15<\mathrm{At} \\
\text { ot } \% \leq 3 \\
0\end{array}$ & $\begin{array}{l}30<\text { Atot } \\
\% \leq 50\end{array}$ & $\begin{array}{l}50<\text { Atot } \\
\%\end{array}$ \\
\hline
\end{tabular}

Table 6. Estimated percentage area by each decay type 
Ultrasonic velocity propagation US, RI.5: concerns the variation of ultrasonic propagation velocity for the decayed materials in respect to the in respect to healthy material.

\begin{tabular}{|l|l|l|l|l|l|}
\hline RI.5 & 1 & 2 & 3 & 4 & 5 \\
\hline Velocit & $\leq 3$ & $3<\Delta_{\mathrm{U}} \%$ & $5<\Delta_{\mathrm{U}} \% \leq$ & $10<$ & $20<\Delta_{\mathrm{U}} \%$ \\
$\mathrm{y}$ & $\%$ & $\leq 5$ & 10 & $\begin{array}{l}\Delta_{\mathrm{U}} \% \\
\leq 20\end{array}$ & \\
$\begin{array}{l}\text { Variati } \\
\text { on U\% }\end{array}$ & & & & & $*$ \\
\hline $\begin{array}{l}\text { Signal } \\
\text { Loss }\end{array}$ & & & & & \\
\hline
\end{tabular}

Table 7. Variation of the Ultrasonic velocity propagation

$>$ Environment characterization RI.6: concerns the environmental impact on the materials and structure, and in particular the environmental characterization as industrial, marine, etc., the exposure to wind and moisture, the annual frost and temperature range of the examined area.

\begin{tabular}{|l|l|l|l|l|l|}
\hline RI.6a & 1 & 2 & 3 & 4 & 5 \\
\hline Industrial & & & & & $*$ \\
\hline Urban & & & & $*$ & \\
\hline Suburban & & & $*$ & & \\
\hline Rural & & $*$ & & & \\
\hline Coastal & & & & & $*$ \\
\hline Mountainous & & & & $*$ & \\
\hline
\end{tabular}

Table 8. Environment characterization

\begin{tabular}{|l|l|l|l|l|l|}
\hline RI.6b & 1 & 2 & 3 & 4 & 5 \\
\hline $\begin{array}{l}\text { Annual } \\
\text { temperature } \\
\text { range }\left(\Delta_{\Delta} \theta\right)\end{array}$ & Small & & Medium & & Large \\
\hline $\begin{array}{l}\text { Frequency } \\
\text { of } \\
\text { temperature } \\
\text { fluctuations } \\
\text { around } 0^{\circ} \mathrm{C} \\
(\Delta \text { freeze })\end{array}$ & $\begin{array}{l}\text { Always } \\
\theta>0^{\circ} \mathrm{C}\end{array}$ & $\begin{array}{l}\text { Vary } \\
\text { Rare } \\
\text { under } \\
0^{\circ} \mathrm{C}\end{array}$ & $\begin{array}{l}\text { Often } \\
\text { fluctuations } \\
\text { under } 0^{\circ} \mathrm{C}\end{array}$ \\
\hline
\end{tabular}

Table 9. Temperature range (around $0{ }^{\circ} \mathrm{C}$ )

\begin{tabular}{|l|l|l|l|l|l|}
\hline RI.6c & 1 & 2 & 3 & 4 & 5 \\
\hline $\begin{array}{l}\text { Average } \\
\text { annual } \\
\text { relative } \\
\text { humidity } \\
\%\end{array}$ & $<40$ & $40-50$ & $50-70$ & $70-90$ & $>90$ \\
\hline
\end{tabular}

Table 10.Relative Humidity RH

\begin{tabular}{|l|l|l|l|l|l|}
\hline RI.6d & 1 & 2 & 3 & 4 & 5 \\
\hline Exposure to strong winds & & & & & $*$ \\
\hline Exposure to medium winds & & & $*$ & & \\
\hline Protection against winds & $*$ & & & & \\
\hline
\end{tabular}

Table 11.Surface exposure to wind $>\quad$ Type and working treatment of architectural surface RI.7: concerns the material susceptibility to decay in relation to the type or the working treatment of the architectural surface.

\begin{tabular}{|l|l|l|l|l|l|}
\hline RI.7 & 1 & 2 & 3 & 4 & 5 \\
\hline $\begin{array}{l}\text { Architectural elements - } \\
\text { decoration }\end{array}$ & & & & & $*$ \\
\hline Rough surface & & & & $*$ & \\
\hline Surface of moderate roughness & & & $*$ & & \\
\hline Surface of low roughness & & $*$ & & & \\
\hline
\end{tabular}

Table 12. Type of Architectural surface

All these risk indicators cover an array of characteristic quantitative or qualitative parameters that can be stored and handled by the documentation system and define the monument and its components. They can be further ranked according to their importance, allowing calculation of an overall risk index. $W 1+W 2 W 3+\cdots W n$

$$
\mathbf{R I}_{\text {total }}=\frac{W_{2} R I_{1}+W_{2} R I_{2}+W_{2} R I_{3}+\cdots W n R M n}{W_{2}+W_{2}+W_{3}+\ldots W n}
$$

Where $\quad W=$ weight factor expressing the percentage of participation of each risk indicator to the final risk index (range 0-5)

$\mathrm{RI}=$ risk indicator

$\mathrm{RI}_{\text {total }}=$ final risk index (range 1-5)

The Risk index can be used as a tool that supports the scientific decision making procedure regarding preventive conservation and conservation interventions.

\section{CONCLUSIONS}

Risk evaluation for cultural heritage assets is a basic step towards sustainable maintenance and preservation. It implies the assessment of its resilience to external or internal alterations and to various hazards and can be defined as the identification of all potential hazards affecting it and the evaluation of the asset's vulnerability (building materials and building structure conservation state). Potential hazards for cultural heritage are complex and range among long term natural processes, sudden events and human impact as well as certain degradation processes within materials and structural elements due to physical and chemical procedures. Therefore risk evaluation should reveal the specific risk factors that decisively contribute to a heritage asset's state of conservation and determine its resilience against various threats.

A prerequisite for risk indicators identification and development is the existence of an organised source of comparable and interoperable data about heritage assets properties, a need that is served by integrated documentation protocols and more specifically by protocols of advanced diagnostics. They become a useful tool of an asset's conservation state investigation, performing materials characterization, decay and damage diagnosis and vulnerability identification. They provide with the guidelines for revealing the actual degradation processes responsible for the asset's vulnerability, based on the requirements of a typical diagnostic study and structural analysis methodology, generated by a necessity for quality control application in building and/or conservation materials 
and structures and having been harmonized with appropriate standards. The analysis of these parameters is essential to the study of the decay pathology of the monument and for the detection of the actual risk factors affecting it.

The development of risk indicators regarding degradation processes, draws upon data collected and organized in the integrated protocols for the identification of all risks that affect the heritage asset and further requires a series of steps like the detailed analysis of the risk, the evaluation of the identified risk, the assignment of a quantitative or qualitative designation to the risk and its management, in order to result in a set of specifically described, measurable and clearly interpreted indicator.

Furthermore, the development of risk indicators needs the establishment of critical limits which determine whether deterioration level is accepted or not. Within this process the simple criteria of risk analysis are further elaborated into becoming risk indicators, able to inform about an asset's resilience to various impacts and loads.

All these risk indicators cover an array of characteristic quantitative or qualitative parameters that can be stored and handled by the documentation system and define the monument and its components. They can be further ranked according to their importance, allowing calculation of an overall risk index as the tool that supports the scientific decision making procedure regarding preventive conservation and conservation interventions. The development of risk indicators regarding degradation processes is the basic step towards uptaking efficient management, preventive conservation and strategic planning for heritage assets.

References and/or Selected Bibliography

Accardo, G. et al., 2003. Risk Map: a project to aid decisionmaking in the protection, preservation and conservation of cultural heritage, In: Conservation Science, Edinburgh, Scotland.

Binda L., Saisi A. Tiraboschi C., 2000, Investigation Procedures for the diagnosis of the historic masonries, Construction and Building Materials, 14, pp.199-233

Chela, G., 2006, Development and use of necessity indices for the diagnostic study of monuments and buildings, MSc Dissertation, National Technical University of Athens, Greece.

ICOMOS. International Scientific Committee for Stone, 2008, ICOMOS-ISCS: Illustrated glossary on stone deterioration patterns, Vol. XV, ICOMOS-ISCS, Paris, 78 p., illus.

Kioussi, A., Labropoulos, K., Karoglou, M., Moropoulou, A., Zarnic, R., 2011, Recommendations and strategies for the establishment of a guideline for monument documentation harmonized with the existing European standards and codes. Journal Geoinformatics FCE CTU 6, pp. $178-184$

Kioussi, A., Karoglou, M., Bakolas, A., A. Moropoulou, A., 2013a, Integrated Documentation Protocols enabling Decision Making in Cultural Heritage Protection. Journal of Cultural Heritage, 14 (3), Supplement, pp. e141-e146

Kioussi, A., Skordaki, N., Karoglou, M., Bakolas, A., Moropoulou, A., 2013b, Documentation based on standards for non destructive control and materials characterization through a diagnostic study for the protection of Cultural Heritage, In: 5th International Conference on NDT, Athens, Greece, In Press.
Mazzolani, ,F., 2010. Urban Habitat Constructions Under Catastrophic Events: COST C26 Action, Final Report, University of Naples Federico II, Italy.

Moropoulou, A., Chandakas, B., Togkalidou, T., Karoglou, M., Padouvas, E., 2003, A new methodology for quality control and monitoring of historic buildings: A tool for lifetime engineering, In: 2nd Int. Symp., ILCDES Integrated Life-time Engineering of Buildings and Civil Infrastructures, Kuopio, Finland, pp. 269-274

Moropoulou A., Labropoulos K., 2010, Characterization of building stone and diagnosis of decay in cultural monuments in Archaeo-Materials: Archaeological, archaeometrical and cultural approaches, Papazissis, pp. 255-291.

Moropoulou, A., Kioussi, A., Karoglou, M., Bakolas, A., Georgousopoulos, G. Chronopoulos, M., 2012, Innovative protocols for integrated diagnostics on historic materials and structures, In: Structural Faults + Repair, Edinburgh, Scotland, cd proceedings, pp.397- 399.

Moropoulou, A., Labropoulos, C. K, Delegou., T. E., Karoglou, M., Bakolas, A., 2013, Non-destructive techniques as a tool for the protection of built cultural heritage, Construction and Building Materials, In Press, Corrected Proof.

Stovel, H. 1998. Risk preparedness: A Management Manual for World. Cultural Heritage, ICCROM. ICOMOS, Rome. 